\title{
A cross-sectional survey examining motivation and beliefs to participating in a web-based prospective cohort study on nutrition and health among individuals with a low socioeconomic status
}

Mélina Côté ${ }^{1}$, Stéphanie Harrison ${ }^{1}$, Annie Lapointe ${ }^{1}$ Catherine Laramée , Sophie Desroches ${ }^{1}$, Simone Lemieux $^{1}$, Benoît Lamarche ${ }^{1}$ and Ariane Bélanger-Gravel ${ }^{2,3^{*}}$

\begin{abstract}
Background: Prospective cohort studies may support public health efforts in reducing health inequalities. However, individuals with a low socioeconomic status (SES) are generally underrepresented in health research. This study aimed to examine the intention and determinants of intention of individuals with a low SES towards participation in a Web-based prospective project on nutrition and health (NutriQuébec) in order to develop recruitment and retention strategies.

Methods: A cross-sectional survey based on the Theory of planned behaviour was conducted in the Province of Québec, Canada. Low SES individuals (high school or less and annual household income $<\$ 55,000$ CAN) were recruited through a Web panel of a polling firm to assess intention, attitude, subjective norm and perceived behavioural control (PBC) towards participation in the NutriQuébec project. Linear regression and logistic regression analyses were conducted.

(Continued on next page)
\end{abstract}

\footnotetext{
* Correspondence: ariane.belanger-gravel@com.ulaval.ca

2Department of Information and Communication, Université Laval, Quebec

City, Québec, Canada

${ }^{3}$ Research Centre of the Quebec Heart and Lung Institute, Quebec City,

Québec, Canada

Full list of author information is available at the end of the article
}

(c) The Author(s). 2020 Open Access This article is licensed under a Creative Commons Attribution 4.0 International License, which permits use, sharing, adaptation, distribution and reproduction in any medium or format, as long as you give appropriate credit to the original author(s) and the source, provide a link to the Creative Commons licence, and indicate if changes were made. The images or other third party material in this article are included in the article's Creative Commons licence, unless indicated otherwise in a credit line to the material. If material is not included in the article's Creative Commons licence and your intended use is not permitted by statutory regulation or exceeds the permitted use, you will need to obtain permission directly from the copyright holder. To view a copy of this licence, visit http://creativecommons.org/licenses/by/4.0/ The Creative Commons Public Domain Dedication waiver (http://creativecommons.org/publicdomain/zero/1.0/) applies to the data made available in this article, unless otherwise stated in a credit line to the data. 
(Continued from previous page)

Results: Mean age of respondents (184 women, 141 men) was 57.6 y (SD =13.6). Attitude ( $\beta=0.54,95 \% \mathrm{Cl}$ : $0.41-$ 0.68) and PBC ( $\beta=0.50,95 \% \mathrm{Cl}$ : $0.37-0.63)$ were significantly associated with intention. Participants who agreed that participating in the study would contribute to an improvement in 1) collective health (odds ratio $[\mathrm{OR}]=2.15,95 \% \mathrm{Cl}$ : 1.27-3.64) and in 2) one's lifestyle habits (OR = 1.70,95\%Cl: 1.04-2.78) were more likely to express positive intention compared to participants who did not agree with these statements. Participants who agreed to participate in the study even 1) in the absence of a financial incentive (OR=1.43,95\%Cl: 1.04-1.99) and even 2) if the completion of questionnaires took up to two hours $(\mathrm{OR}=1.78,95 \% \mathrm{Cl}$ : 1.27-2.48) were also more likely to express high intention. Receiving a personalized brief health assessment $(O R=1.61,95 \% \mathrm{Cl}$ : 1.13-2.30) and the use of simple questions in the questionnaires $(\mathrm{OR}=1.54,95 \% \mathrm{Cl}$ : 1.05-2.25) were facilitating factors associated with high intention. Participants believing that participation would be too time-consuming were less likely to have positive intention $(\mathrm{OR}=0.57$, 95\%Cl: 0.43-0.75).

Conclusions: The development of a positive attitude and a high PBC towards participation in the NutriQuébec project will be necessary to obtain representative data of low SES adults.

Keywords: Low socioeconomic status, Theory of planned behavior, Web-based studies, Beliefs, Recruitment, Retention

\section{Background}

A clear gradient in health was recently observed in Canada among the more socially disadvantaged individuals [1]. It was observed that individuals with a lower socioeconomic status (SES) are more likely to adopt unhealthy lifestyle habits like smoking and being sedentary [2-4]. They are also more likely to have low quality diets and to face food insecurity $[1,3]$. Consequently, low SES groups are more likely to develop chronic diseases, such as cardiovascular diseases and type 2 diabetes, and to have a lower life expectancy $[1,3]$. Health inequalities are the result of interactions between multiple factors, including living conditions, psychosocial factors, health behaviours and genetic factors [1]. Despite this higher burden of diseases, individuals with a low SES do not always benefit from medical advances; this situation potentially leading to an increase in inequalities within the population [5]. Hence, health inequalities are a significant public health concern and reducing them represents a top priority $[1,6]$.

Prospective cohort studies may support public health efforts in reducing health inequalities by providing knowledge about the causes of these inequalities [6]. Such studies may also provide ongoing monitoring of the population's health in the context of implementing and evaluating public health policies [1]. However, these studies, traditionally conducted by phone, postal mail or face-to-face interviews, can be burdensome and costly. Therefore, Web-based cohort studies raised enthusiasm in recent years due to their lower cost and time demand as well as the quality of data [7-9]. Web versions of a sociodemographic questionnaire [10], an anthropometric questionnaire [11] and a $24 \mathrm{~h}$ dietary recall [12] were validated in the NutriNet-Santé France prospective ecohort study. Researchers concluded that data obtained from the Web questionnaires were of equal or superior quality when compared to data obtained from the paperand-pencil versions of these questionnaires. Moreover, Web-based studies allow for an easier access to a larger number of potential participants, eliminating geographical boundaries and favoring easier access to hard-toreach populations $[9,13-15]$. In general, Internet access is now less perceived as a barrier to participate in Webbased studies [14-16] and can even be perceived as a facilitating factor. Indeed, in the NutriNet-Santé France study, half of the participants reported that they would not have participated in the project if it had not been conducted on the Internet [16]. On the other hand, the use of Web-based methods for data collection in health surveys and cohort studies remains a challenge. The European Health Interview Survey (EHIS) has shown that the use of mixed methods for data collection yielded a higher participation rate than the use of Web-based methods only [17]. Furthermore, although the majority of families living with an income lower than $\$ 20,000$ have access to Internet in the context of the present study, a digital divide still exists in societies [18]. Low SES individuals still report lower access to Internet in their household [18] and, in some cases, have lower levels of health literacy and computer literacy due to lower education levels [19]. Considering the growing popularity of Web-based cohort studies and surveillance efforts, implementing strategies to maximize participation of individuals with a low SES in such studies is critical. Moreover, since individuals with a low SES are generally underrepresented in health studies [20, 21], recruitment and retention strategies must be adapted to encourage participation among these populations.

Epidemiological and surveillance research aimed at addressing social inequalities in health does not come 
without challenges. Indeed, transportation and time constraints [22-24], residential instability [22, 25], wrong numbers, disconnected phones and lack of answering machines [13, 22, 25], inability to reach potential participants at initial contact [25], economic constraints [23], mistrust of the Government and research, fear of exploitation as well as lack of knowledge [13, 23, 24] have all been identified as barriers to participating in studies among hard-to-reach populations such as those with a low SES, minority groups, and vulnerable populations. Hard-to-reach individuals are also often excluded from longitudinal studies because of acute medical or psychological conditions, or because of behavioural and social factors like alcoholism and drug abuse [23]. However, the barriers reported in these studies were not documented in the context of participation in Web-based prospective studies and were not conducted according to a validated theoretical framework. This is key because the use of theoretical frameworks to identify facilitators and barriers help in the development of more meaningful messages aimed at promoting the targeted behaviours (i.e., the participation in Web-based studies) [26]. To date, the very few studies that have used a validated theoretical framework to examine barriers towards participation in Web-based surveys were conducted among students or in the general population [27, 28]. Thus, the perceptions and beliefs of individuals with a low SES towards participation in prospective cohort studies remain essentially unknown.

According to the Theory of Planned Behaviour (TPB), the adoption of a given behaviour is determined by individuals' intention (or motivation) to perform the behaviour. In turn, intention is influenced by individuals' attitude (behavioural beliefs; advantages/disadvantages), the subjective norm (normative beliefs; approval/disapproval of significant others) and perceived behavioural control (PBC; control beliefs; facilitators/barriers) [29]. A meta-analysis reported that the TPB could explain 19.3\% of the variance of several health-related behaviours and $44.3 \%$ of the variance of intention [30]. The TPB showed moderate to strong prediction of intention and behaviours across several health domains [31]. In addition, studies have previously used the TPB to examine beliefs related to participation in Web-based surveys [27, 28, 32]. Other studies based on the TPB have also demonstrated how beliefs related to one's health can impact their decision to participate in health programs [33, 34]. Given the strong predictive validity of the TPB [29] and its recognition as a rigorous tool to examine behaviours related to participation in Web-based surveys, this theoretical framework was used in the present study.

A Web-based prospective study providing ongoing monitoring of the population's health could allow evaluating public health policies as well as identifying and addressing health inequalities. Since individuals with a low SES are generally underrepresented in health studies, recruitment and retention strategies must be adapted to encourage participation among these populations in this type of research project. To support the development of effective strategies to recruit and retain individuals with a low SES, the aim of this study was to examine the determinants of intention and associated beliefs among individuals with a low SES toward participation in a Web-based prospective study, the NutriQuébec project, using the TPB [29].

\section{Methods \\ Design and sampling}

The NutriQuébec project is a Web-based, prospective study aimed at examining the impact of nutrition-related public health policies and action plans on the diet of the Québec adult population in Canada. More broadly, the NutriQuébec project aims to examine the associations between diet and health outcomes. To do so, male and female adults (18 years of age or more) are invited to complete a series of yearly core questionnaires through the Web, assessing dietary habits and other lifestyle habits (e.g., physical activity, sedentary behaviours, sleep, etc.), sociodemographic characteristics and general health. The time required to complete the core questionnaires on a yearly basis was estimated to two hours (unpublished data). Participants have a one-month period to complete the set of questionnaires. Participants may be invited to complete additional questionnaires on other nutrition-related issues between each yearly core measurements. A brief personalized assessment of dietary habits is returned yearly to each participant.

A cross-sectional survey was conducted throughout the Province of Québec, Canada (sixteen administrative regions) among adults with a low SES. Respondents were recruited through a Web panel of a polling firm. The polling firm uses a pool of panelists that were randomly recruited among the Québec population to complete online surveys. The polling firm then sends a request to fill out the survey questionnaire to panelists corresponding to the inclusion criteria. The inclusion criteria were 1) to be able to complete a questionnaire in French, 2) to reside in the Province of Québec 3) to have low education (high school or less), and 4) to have low income (gross annual household income $<\$ 55,000$ CAN). Overall, 1370 individuals were invited by the polling firm to complete the survey questionnaire (Fig. 1). Among those, 708 individuals accessed the questionnaire but 383 participants were excluded from the study because they did not meet the inclusion criteria $(n=145)$, accessed the questionnaire after data collection was completed $(n=25)$, unsubscribed from the polling firm panel $(n=2)$ or stopped the questionnaire while 


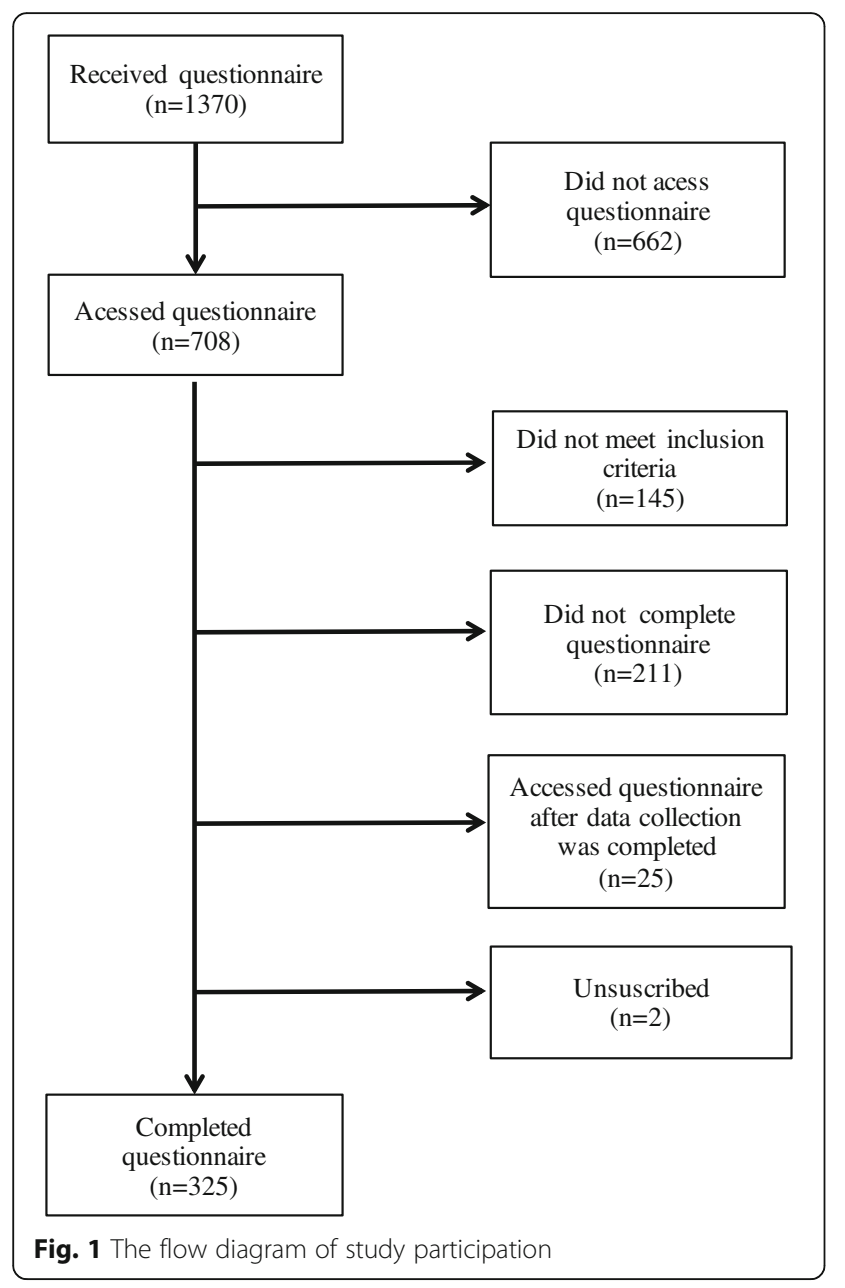

completing it $(n=211)$. Therefore, the data of 325 respondents were retained for analysis. The survey questionnaire was completed by participants on the Internet between the 11th and 20th of October 2018 and lasted approximately $15 \mathrm{~min}$ (Supplementary file 1). Respondents gave their implicit and anonymous consent by answering the questionnaire. The survey was approved by the Ethics Committee of Université Laval (2018-042/07-06-2018).

\section{Measurement}

The survey questionnaire was developed for the purposes of the present study. It was developed following Ajzen's guidelines for developing a TPB questionnaire [29] and included the behavioural and control beliefs identified in a preliminary elicitation study [32]. Briefly, four semi-structured focus groups, each comprising seven French-speaking adults, took place to identify behavioural beliefs, normative beliefs and control beliefs towards a hypothetical participation in the NutriQuébec project. The participants included in the focus groups were recruited through non-profit organizations (food banks, community organizations) known to serve populations living in deprived sectors of Québec City. Thereafter, two coders conducted an independent content analysis to classify the respondent's answers in themes and to identify salient beliefs. The final classification of the beliefs was determined by consensus between the two coders. A third coder was involved when the two coders disagreed on some classifications. Since the aim of the present study was to develop strategies to optimize the recruitment and retention of individuals with a low SES in the NutriQuébec project, only beliefs that were the most relevant in the context of this project were included in the survey questionnaire. For example, although no or limited access to Internet was identified as a salient barrier to participation, this specific belief was not assessed in the survey because providing alternative methods such as sending a paper-and-pencil questionnaire by postal mail or providing direct support for Internet access was not considered in the NutriQuébec project because of feasibility issues. Similarly, factors that were out of the research team's control (e.g., illness, little or no knowledge about Internet, etc.) or that were mentioned in only one out of the four focus groups were not included in the survey questionnaire. Finally, although budget constraints hinder the research team from offering monetary incentives or gift cards to participants, this was assessed anyways in order to grasp interest in participation if no incentive was offered. Before launching the survey, the questionnaire was evaluated by six experts in the fields of behaviour change, health communication, nutrition, and epidemiology to validate the clarity and the intelligibility of the questions.

Intention was assessed using three questions (Cronbach $\alpha=0.81$ ) with the following items: 1) "I intend to participate in the NutriQuébec project", 2) The chances that I participate in the NutriQuébec project are ... and, 3) I will participate in the NutriQuébec project. The answer choices varied from very unlikely to very likely and from very low to very high. Attitude was assessed using three questions (Cronbach $\alpha=0.89$ ): For me, participating in the NutriQuébec project would be ... 1) very unpleasant/very pleasant, 2) very useless/very useful and, 3) very unsatisfying/very satisfying. Behavioural beliefs (five advantages and one disadvantage) were assessed using six questions. Injunctive norm was assessed using two questions with the following items: 1) The most important people to me would think that I should participate in the NutriQuébec project and 2) If I were to participate in the NutriQuébec project, most people who are important to me would ... strongly disagree/strongly agree. Descriptive norm was assessed using one question: Many people I know may be interested in participating in the NutriQuébec project. Subjective norm represented the composite mean score of these three items and the 
Cronbach alpha was 0.66. Normative beliefs were not assessed in the present study questionnaire because no modal normative beliefs were identified during the preliminary elicitation study. PBC was assessed using three questions: 1) I feel that I am capable of participating in the NutriQuébec project, 2) I am confident that I can overcome any obstacles that may prevent me from participating in the NutriQuébec project and, 3) For me, participating in the NutriQuébec project would be ... very difficult/very easy (Cronbach $\alpha=0.82$ ). Control beliefs were assessed using five questions (three facilitators and two barriers; see the Additional File for detailed description of the beliefs assessed). All psychosocial variables were measured using answer choices on five-point Likert or semantic scales. Participants also answered questions pertaining to their sociodemographic and socioeconomic position (sex, age, administrative area, education, income), Internet access at home as well as perceived computer skills. Perceived computer skills were assessed on a five-point Likert scale using the following question: How would you rate your ability to browse the Internet?

\section{Statistical analysis}

Sample size estimations were based on a study by Rashidian et al., who determined the number of participants to conduct sufficiently powered TPB studies [35]. Continuous variables are described as means and standard deviations while categorical variables are described as proportions. Data were analysed using a stepwise approach. First, multivariate linear regression models were used to identify how the three TPB constructs were associated with intention to participate in NutriQuébec, as suggested by Fishbein and Yzer [36]. We then examined, using multivariate models, associations between behavioural and control beliefs and their associated TPB constructs. This analysis was restricted to the TPB constructs that showed significant associations with intention, as identified in the first step. In all univariate and multivariate analyses, effect sizes are reported as standardized betas $(\beta)$. Finally, logistic regression analyses were used to identify the behavioural and control beliefs that showed the strongest associations with intention to participate in NutriQuébec project. In this analysis, odds ratios (OR) reflected the likelihood of having a positive intention to participate, using negative intention as a reference $(\mathrm{OR}=$ 1.0). For that purpose, intention score was dichotomized with mean scores $>3$ representing positive intention and mean scores $\leq 3$ representing neutral or negative intention. TPB constructs and behavioural and control beliefs were treated as continuous variables in all analyses. All models were adjusted for sex, age, perceived ability to browse the Internet and for previous participation in studies on lifestyle habits conducted on the Internet. SAS Studio (v 3.71) was used for all analyses and p-values below 0.05 (two-tailed) were set to indicate the level of statistical significance.

\section{Results}

\section{Participants' characteristics}

Sample size estimations determined that 148 participants were minimally needed to conduct the study. The sample comprised 184 women and 141 men with a mean age of 57.6 years $(\mathrm{SD}=13.6)$. Sociodemographic and socioeconomic characteristics of the participants are presented in Table 1 . The majority of participants had a high school degree as the highest education level attained (89\%), reported being moderately competent, very competent or expert in browsing the Internet (86\%), and had access to Internet at home (98\%).

\section{Linear regression analysis linking constructs with intention}

The multivariable linear regression analysis revealed that attitude $(\beta=0.54,95 \%$ CI: $0.41-0.68)$ and PBC $(\beta=0.50$, 95\% CI: $0.37-0.63)$ were significantly associated with intention score, explaining $67 \%$ of its variance. Subjective norm was not associated with intention to participate in the NutriQuébec project $(\beta=0.05,95 \%$ CI: $-0.05-0.16$ ). Similar results were obtained among men and women when analyzed separately (data not shown).

Table 1 Sociodemographic and Socioeconomic Characteristics of the Sample

Variables

Age (years), mean (SD) $57.6(13.6)$

N (\%)

Gender

Male $141(43)$

Female $184(57)$

Education

None 36 (11)

High school or equivalent 289 (89)

Annual household gross income

$0-\$ 15,000$ CAN

$\$ 15,000-\$ 24,999$ CAN

67 (20)

$\$ 25,000-\$ 34,999$ CAN

$84(26)$

$\$ 35,000-\$ 54,999$ CAN

$136(42)$

Internet access at home

Yes

320 (98)

No

5 (2)

Computer skills

Not at all competent

4 (1)

Hardly competent

42 (13)

Moderately/rather competent 179 (55)

Very competent

$82(25)$

Expert $18(6)$ 
Linear regression analysis linking behavioural and control beliefs with corresponding constructs

Table 2 shows the associations between respondents' behavioural and control beliefs and attitude and PBC respectively. The behavioural beliefs (independent variables) that were significantly associated with attitude (dependant variable) in multivariate analyses were: 1 ) contributing to improving collective health $(\beta=0.23$, $p=0.0003), 2$ ) having the opportunity to improve one's lifestyle habits $(\beta=0.30, p=<0.0001)$, and 3$)$ the fact that completing the survey questionnaires would be too time-consuming $(\beta=-0.18, p=<0.0001)$. The control beliefs (independent variables) that were significantly associated with PBC (dependant variable) were: 1$)$ receiving a personalized brief health assessment $(\beta=0.14$, $p=0.0006), 2)$ the use of simple questions $(\beta=0.13, p=$ $0.0062), 3)$ participating in the research project even without financial incentives $(\beta=0.11, p=0.0011)$, and 4) participating in the research project even if the completion of the questionnaires would take two hours $(\beta=0.19, p=<0.0001)$.

\section{Logistic regression analysis of intention to participate in the NutriQuébec project}

Figure 2 shows the results of the logistic regression analysis aimed at identifying beliefs that are associated with intention to participate in the NutriQuébec project. This analysis showed that participants who scored favorably for behavioural and control beliefs associated with attitude and $\mathrm{PBC}$ respectively also expressed a greater likelihood to participate in NutriQuébec than participants with negative scores for behavioural and control beliefs.

\section{Discussion}

NutriQuébec is a Web-based prospective study on diet and health among adults from the Province of Québec, Canada. The objective of this study was to examine the determinants of intention and its associated beliefs towards participation in the NutriQuébec project, targeting hard-to-reach individuals with a low SES. The results showed that attitude and PBC were both associated with potential participation in the NutriQuébec project and highlighted some key beliefs that should be considered to maximize recruitment and retention of individuals with a low SES. These study results are of most relevance to the NutriQuébec project. These findings could also be of interest to other prospective Web-based studies wanting to optimize recruitment and retention strategies among individuals with a low SES, although not being necessarily generalizable to all other Web-based studies because of the specific elements of the NutriQuébec project.

Results suggest that favouring a positive attitude and a high PBC towards participation will be essential, whereas developing messages around some form of social

Table 2 Multivariate Analyses of Behavioural and Control Beliefs Associated with Attitude and PBC Towards Participation in NutriQuébec

\begin{tabular}{|c|c|c|c|}
\hline Items & Standardized ß & $\boldsymbol{P}$-value* & $95 \% \mathrm{Cl}$ \\
\hline \multicolumn{4}{|l|}{ Behavioural beliefs associated with attitude } \\
\hline \multicolumn{4}{|l|}{ Advantages } \\
\hline Contributing to improving collective health & 0.23 & 0.0003 & $0.11-0.35$ \\
\hline Having the opportunity to improve one's lifestyle habits & 0.30 & $<0.0001$ & $0.17-0.43$ \\
\hline Having the opportunity to improve the family's lifestyle habits & 0.02 & 0.73 & $-0.09-0.13$ \\
\hline Learning new knowledge on health & 0.05 & 0.46 & $-0.09-0.19$ \\
\hline Contributing to advancing science & 0.08 & 0.15 & $-0.03-0.19$ \\
\hline \multicolumn{4}{|l|}{ Disadvantages } \\
\hline Too time-consuming to complete the questionnaire & -0.18 & $<0.0001$ & $-0.24--0.12$ \\
\hline Model $\mathrm{R}^{2}$ & 58.8 & & \\
\hline \multicolumn{4}{|l|}{ Control beliefs associated with PBC } \\
\hline \multicolumn{4}{|l|}{ Facilitating factors } \\
\hline Receiving a personalized brief health assessment & 0.14 & 0.0006 & $0.06-0.22$ \\
\hline The use of simple questions & 0.13 & 0.0062 & $0.04-0.23$ \\
\hline Anonymity & -0.02 & 0.6597 & $-0.10-0.06$ \\
\hline \multicolumn{4}{|l|}{ Barriers } \\
\hline Participating even without financial incentives & 0.11 & 0.0011 & $0.04-0.18$ \\
\hline Participating even if the completion of the questionnaires would take two hours & 0.19 & $<0.0001$ & $0.11-0.26$ \\
\hline Model $\mathbf{R}^{2}$ & 45.2 & & \\
\hline
\end{tabular}

${ }^{*} p$-values and $95 \% \mathrm{Cl}$ were found using linear regression models 


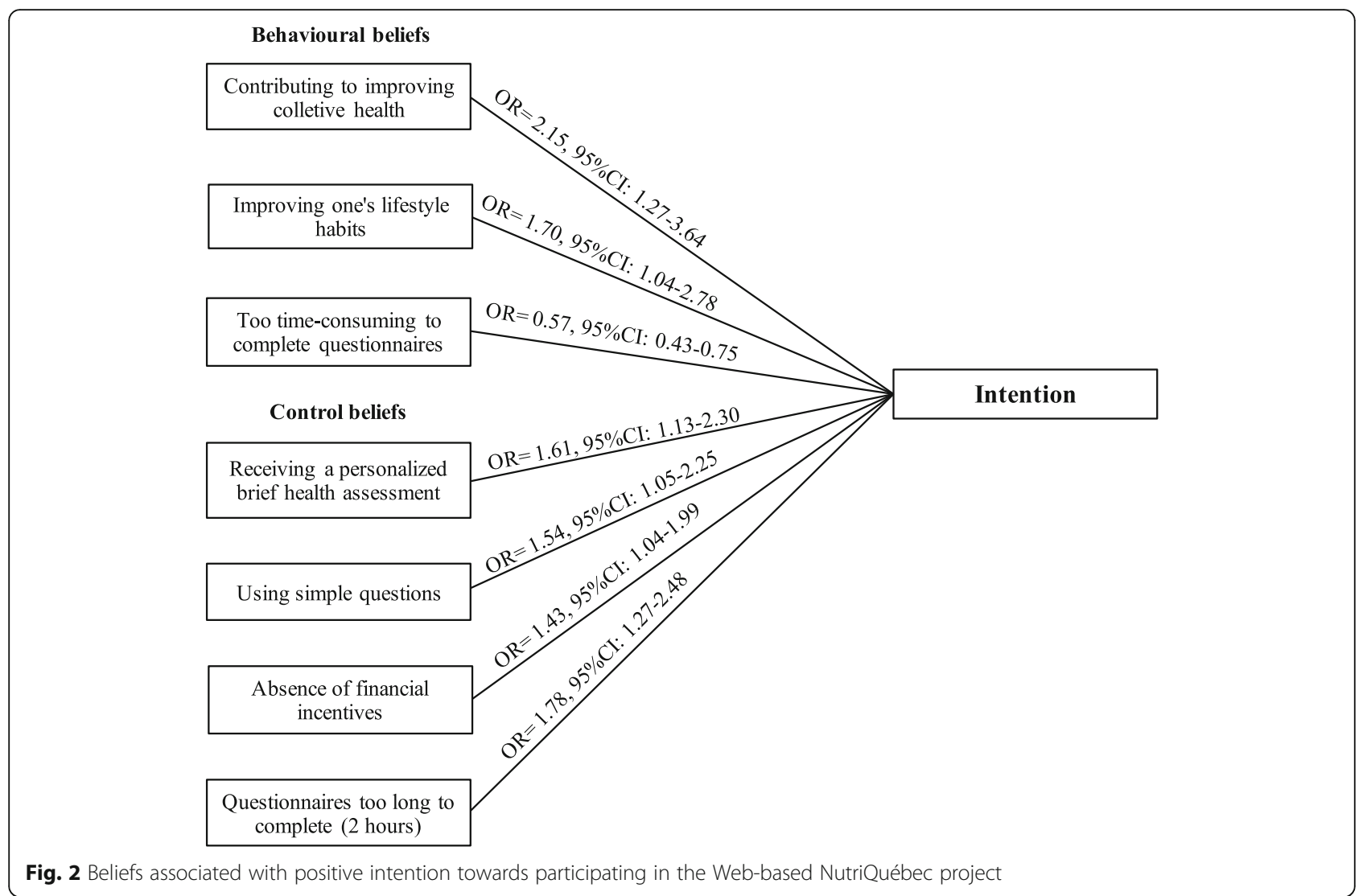

approval is unlikely to facilitate recruitment of individuals with a low SES. This is consistent with the results from our preliminary elicitation study, in which no salient normative beliefs clearly emerged towards potential participation in the NutriQuébec project among adults living in deprived urban areas [32]. A possible reason why subjective norm does not result in a significant determinant of intention could be the fact that the behaviour, participating in the NutriQuébec project, does not directly impact a person's environment or significant others. Similarly, participants in a study evaluating the intention to consult a blog delivered by a registered dietitian to improve their dietary habits reported that this action did not require the approval of others, since it was considered rather personal [37].

Our results are, however, at odds with data from previous studies on this topic. The study by Farmer et al. [38], which examined the TPB determinants of intention to participate in a medical research project among low SES and African American women, showed that attitude, $\mathrm{PBC}$ and perceived social norms were all associated with intention. However, it is noteworthy that the social norms related themes were trust (or mistrust) in researchers and negative perceptions about the behaviour of researchers rather than focussing on others' approval/ disapproval [38]. Moreover, this study was not about participation in Web-based surveys. The study by Heerwegh et al. [27] also reported that positive attitudes, a higher degree of $\mathrm{PBC}$ and a positive subjective norm were all associated with a higher intention to participate in a Web-based survey among the general population. Similarly, Bosnjak et al. [28] observed that PBC best predicted intention to participate in a Web-based survey among undergraduate students, followed by attitude and subjective norm. Differences in results between our and previous study results may be explained to a large extent by the nature of the study populations with regards to SES. To our knowledge, the present study is the first to identify the determinants of intention to participate in a Web-based study on diet and health among individuals with a low SES specifically. Discrepancies between results also highlight a basic premise of the reasoned action approach (from which the TPB relies): beliefs and determinants of a behaviour are highly context-dependant and should always be assessed when attempting to intervene in a target population [39]. Nonetheless, results seem to be coherent with the fact that participation in a study relies mostly on attitude and PBC.

The positive behavioural beliefs (or perceived advantages) that were significantly associated with a positive attitude and intention towards participation in the Webbased NutriQuébec project pertained to the potential 
contribution to improving collective health and one's lifestyle habits. Altruistic motivation to participate in research projects has been reported previously [16, 38, 40, 41]. For instance, African American and low SES women mentioned in focus groups that they would participate in a research project if it could possibly benefit others in the future [38]. Another study on the motives towards participation in a Web-based prospective study reported that the majority of participants took part in the research project to contribute to advancing public health research [16]. Contributing to improving the population's health and the environment was also identified as benefits to participating in a prospective cohort study [41] as well as in a study regarding the creation of a research database comprising personal, clinical and genetic information [40]. Interestingly, the second positive behavioural belief associated with participation in the NutriQuébec project pertained to the opportunity to improve one's health. This is in line with previous studies on altruism, which highlighted that pure altruism is not always observed and that individuals expect some form of reward in exchange for their time and participation $[38,42]$. This suggests that framing participation in the Web-based NutriQuébec project as an altruistic act may be a promising strategy to recruit individuals with a low SES. However, persuasive messages may also need to highlight the potential opportunity to learn more about one's health and even improve it. The fact that obtaining a personalized brief health assessment was among the significant discriminant facilitating factors further supports this assertion. The recruitment and probably the retention of participants with a low SES in the NutriQuébec project are therefore likely to be facilitated by providing a brief health assessment as a participation reward. Similar findings were reported by Yamamoto et al., where participants with a high level of motivation to participate in a study mentioned that having access to their own results was a motivation factor [41]. Nevertheless, providing individualized feedback on diet and health raises concerns in the context of conducting a prospective study aimed at examining the associations between the population's health and the impact of policies on health since providing a health assessment might be considered as an intervention by itself [43]. Thus, providing feedback needs to be balanced between participation reward and satisfaction and behaviour change motivation to limit potential bias in estimations. Strategies to control for potential impacts of the feedback mechanisms on participants' behaviours over time may also need to be implemented to ensure that they can be captured and adjusted for in the analyses.

The burdensomeness of taking time to fill out numerous questionnaires was a negative behavioural belief (or a disadvantage) associated with participating in the NutriQuébec project. Similarly, it was observed from a longitudinal study with weekly Web surveys over 2.5 years that some participants found the long-term and repetitive nature of surveys tedious [44]. The time burden associated with participation of low SES or minority populations in studies has also been documented elsewhere [22, 23, 45], suggesting that the idea of being considerably committed to a study discourages participants and may increase attrition over time. Considering the fact that prospective studies necessarily involve repeated observations/measures over long periods of time, strategies in data collection must be adopted to make sure that participants perceive more benefits than disadvantages. Retention strategies in longitudinal studies include the reduction of participant burden (convenience, simplicity, not feeling judged, etc.) [46] and taking into account participant suggestions regarding data collection [47].

Participants who declared that they would participate in the research project even in the absence of monetary incentives expressed a higher degree of $\mathrm{PBC}$ and intention. This suggests that providing a financial incentive to increase participation in a Web-based longitudinal study may not be necessary among individuals with low SES. This is consistent with findings by Edwards et al., which showed no evidence that a monetary incentive encouraged participants to complete Webbased surveys [48]. Instead, they reported that offering a non-monetary incentive increased the odds of completing a Web-based survey by two-folds [48]. It should be noted that findings from this Cochrane Review were not necessarily drawn from studies conducted only among SES populations. This is also consistent with our elicitation study, in which all focus groups expressed an interest in non-monetary incentives, like receiving a health assessment [32]. Likewise, results from the present study showed that receiving a personalized brief health assessment was associated with high $\mathrm{PBC}$ and high intention to participate in the NutriQuébec project. On the other hand, other studies have shown that providing a financial incentive was effective to encourage low-income, unemployed or hard-to-reach individuals to participate in a study [49-51]. Yu et al. reported that the use of a modest monetary incentive $(\$ 10)$ in a longitudinal study increased the number of returned surveys [52]. Taken together, these results suggest that the effect of a monetary incentive on recruitment and retention of participants remains uncertain, particularly for long surveys, and more studies on this topic are needed to clarify the impact of such an approach on participation in Webbased research projects.

Studies have often reported an inverse association between the length of the questionnaires and response rate [48, 53-55]. Inversely, results from another study showed that longer questionnaires were associated with higher participation rates, which could possibly be 
explained by the fact that a greater involvement in the study seemed to increase interest in research participation [56]. Participation in epidemiological studies has decreased in the past decades [46], emphasizing the importance of identifying underlying factors, including questionnaire length. Considering the fact that the NutriQuébec project requires completing questionnaires once a year, it was important to know if the length of these questionnaires would be a barrier to participate in the study for individuals with a low SES. Our results suggest that participants who would participate in the research project even if the questionnaires took two hours to complete had a high degree of $\mathrm{PBC}$ and high intention. Allowing participants to complete questionnaires over an extended period of time rather than during the predefined one-month window of time may decrease the perception that participation is burdensome and increase self-efficacy toward this behaviour. However, at study onset, it was decided not to modify the period to fill out all questionnaires to minimize time disparity in the measurement of the various health behaviours.

The use of simple questions was significantly associated with high $\mathrm{PBC}$ and high intention towards participation in the NutriQuébec project. This result highlights the significant need to address literacy issues to recruit and retain individuals with a low SES in prospective research projects. Consistent with this, a study reported that individuals with low literacy were more likely to prefer simple sentences when presented with six different descriptions for each predetermined research term ('randomisation', 'informed consent', 'confidentiality' and 'why carry out research?') [57]. Low literacy is more prevalent among adults with a low SES. Indeed, among the Québec adults (18-65 years) who do not have a high school diploma, unemployed and low literacy persons are overrepresented [58]. Additionally, a study reported that adults with low health literacy and numeracy were significantly less interested in participating in research projects, most probably because of the difficulties associated with understanding consent forms and perceived risks pertaining to the project as well as the skills needed to complete survey questionnaires [59]. To help recruit individuals with a low SES among the Québec population, efforts need to be made to simplify the questionnaires and test them for clarity within low SES groups. Efforts will also be made to present and explain the study in simple terms on the NutriQuébec website.

\section{Strengths and limitations}

As indicated above, this is the first study, to our knowledge, that examined determinants of intention of participating in a Web-based prospective cohort study as well as the influence of behavioural and control beliefs on this intention among a sample of adults with a low SES. The TPB was used as a validated framework for the basis of this study, which is another strength because of its strong predictive capacity. Also, participants were recruited from sixteen different administrative regions in the Province of Québec, Canada, which suggests a good representation of individuals with a low SES across the Province. On the other hand, this study was only conducted in French, which may not represent the beliefs of English-speaking Quebecers, as well as those of immigrants or Indigenous people who cannot complete the survey questionnaire in French. Findings may also not be representative of all low SES individuals in Québec considering that the vast majority of participants reported having access to Internet and being competent using the Internet, which is most likely related to recruitment via a Web panel of a polling firm. Additionally, given the relatively low response rate, a selection bias cannot be ruled out. Indeed, it is possible that the individuals who participated in the study had a greater interest in nutrition and therefore were more prone to having a higher intention of participating in the NutriQuébec project as well as to perceiving more advantages and fewer barriers. Findings may also not be generalizable to all prospective Web-based studies considering the specific elements of the NutriQuébec project. Lastly, the cross-sectional nature of the study is also a limitation. Future studies would benefit from identifying whether intention leads to behaviour within this population.

\section{Conclusions}

This study examined for the first time the intention of participating in a Web-based prospective cohort study among adults with a low SES, as well as the influence of behavioural and control beliefs on intention. Using the TPB, we observed that favouring a positive attitude and a high PBC towards participation in a Web-based project are likely to be key factors facilitating recruitment among adults with a low SES. Furthermore, altruism, improving lifestyle habits and receiving a health assessment were significant behavioural and control beliefs that should be leveraged in the recruitment and retention strategies to encourage participation in the NutriQuébec project. Questionnaires should also be as simple and short as possible to favour participation of adults with a low SES. These results are of importance for future Web-based prospective studies in order to adapt recruitment and retention strategies to help capture data from all groups of the population, particularly those that are more socially disadvantaged. 


\section{Supplementary information}

Supplementary information accompanies this paper at https://doi.org/10. 1186/s12889-020-08467-1.

Additional file 1: Supplementary File 1. The TPB Survey

Questionnaire.

\section{Abbreviations}

PBC: Perceived behavioural control; SES: Socioeconomic status; TPB: Theory of planned behaviour

\section{Acknowledgements}

We express our gratitude to the study participants, without whom the study would not have been possible.

\section{Authors' contributions}

$M C$ and $\mathrm{SH}$ wrote a first draft of this paper and performed the analysis with $A B G$. SD, SL, BL and ABG designed the study. $A L$ and $C L$ coordinated the study. All authors have reviewed and accepted the final version of the manuscript.

\section{Funding}

Financial support for this study was provided by the FRQS Réseau de recherche en santé cardiométabolique, diabète et obésité. The funder played no role in research design, data collection, data analysis, manuscript write-up or decision to publish.

\section{Availability of data and materials}

The datasets used and/or analyzed during the current study are available from the corresponding author on a reasonable request.

\section{Ethics approval and consent to participate}

Respondents gave their implicit and anonymous consent by answering the questionnaire. The survey was approved by the Ethics Committee of Université Laval (2018-042/07-06-2018).

\section{Consent for publication}

Not applicable.

\section{Competing interests}

The authors declare that they have no competing interests.

\section{Author details}

${ }^{1}$ Institute of Nutrition and Functional Foods (INAF), Université Laval, Quebec City, Québec, Canada. ${ }^{2}$ Department of Information and Communication, Université Laval, Quebec City, Québec, Canada. ${ }^{3}$ Research Centre of the Quebec Heart and Lung Institute, Quebec City, Québec, Canada.

Received: 4 November 2019 Accepted: 5 March 2020

\section{Published online: 17 March 2020}

\section{References}

1. Public Health Agency of Canada, Pan-Canadian Public Health Network. Key health inequalities in Canada : a national portrait : executive summary. Ottawa: Public Health Agency of Canada; 2018.

2. Katikireddi SV, Whitley E, Lewsey J, Gray L, Leyland AH. Socioeconomic status as an effect modifier of alcohol consumption and harm: analysis of linked cohort data. Lancet Public Health. 2017;2(6):e267-e76.

3. Psaltopoulou T, Hatzis G, Papageorgiou N, Androulakis E, Briasoulis A, Tousoulis D. Socioeconomic status and risk factors for cardiovascular disease: impact of dietary mediators. Hell J Cardiol. 2017;58(1):32-42.

4. Martinez SA, Beebe LA, Thompson DM, Wagener TL, Terrell DR, Campbell JE. A structural equation modeling approach to understanding pathways that connect socioeconomic status and smoking. PLoS One. 2018;13(2): e0192451.

5. Weiss D, Rydland HT, Oversveen E, Jensen MR, Solhaug S, Krokstad S. Innovative technologies and social inequalities in health: a scoping review of the literature. PLoS One. 2018;13(4):e0195447.

6. Marmot M, Bell R. Social inequalities in health: a proper concern of epidemiology. Ann Epidemiol. 2016;26(4):238-40.
7. Smith B, Smith TC, Gray GC, Ryan MA. Millennium cohort study T. when epidemiology meets the internet: web-based surveys in the millennium cohort study. Am J Epidemiol. 2007;166(11):1345-54.

8. Toledano MB, Smith RB, Brook JP, Douglass M, Elliott P. How to establish and follow up a large prospective cohort study in the 21st century--Lessons from UK COSMOS. PLoS One. 2015;10(7):e0131521.

9. Rhodes SD, Bowie DA, Hergenrather KC. Collecting behavioural data using the world wide web: considerations for researchers; 2003.

10. Vergnaud AC, Touvier M, Mejean C, Kesse-Guyot E, Pollet C, Malon A, et al. Agreement between web-based and paper versions of a sociodemographic questionnaire in the NutriNet-Sante study. Int J Public Health. 2011;56(4):407-17.

11. Touvier M, Mejean C, Kesse-Guyot E, Pollet C, Malon A, Castetbon K, et al. Comparison between web-based and paper versions of a self-administered anthropometric questionnaire. Eur J Epidemiol. 2010;25(5):287-96.

12. Touvier M, Kesse-Guyot E, Mejean C, Pollet C, Malon A, Castetbon K, et al. Comparison between an interactive web-based self-administered $24 \mathrm{~h}$ dietary record and an interview by a dietitian for large-scale epidemiological studies. Br J Nutr. 2011;105(7):1055-64.

13. Bonevski B, Randell M, Paul C, Chapman K, Twyman L, Bryant J, et al. Reaching the hard-to-reach: a systematic review of strategies for improving health and medical research with socially disadvantaged groups. BMC Med Res Methodol. 2014;14(1):1-29.

14. Whitaker C, Stevelink S, Fear N. The use of Facebook in recruiting participants for Health Research purposes: a systematic review. J Med Internet Res. 2017;19(8):e290.

15. Topolovec-Vranic J, Natarajan K. The Use of Social Media in Recruitment for Medical Research Studies: A Scoping Review. J Med Internet Res. 2016;18(11):e286.

16. Mejean C, Szabo de Edelenyi F, Touvier M, Kesse-Guyot E, Julia C, Andreeva VA, et al. Motives for participating in a web-based nutrition cohort according to sociodemographic, lifestyle, and health characteristics: the NutriNet-Sante cohort study. J Med Internet Res. 2014;16(8):e189.

17. Braekman E, Charafeddine R, Demarest S, Drieskens S, Tafforeau J, Van der Heyden J, et al. Is the European Health Interview Survey online yet? Response and net sample composition of a web-based data collection. Eur J Public Health. 2019. epub:1-6.

18. Bourget C, Lacombe M-È. Portrait numérique des foyers québécois 2017. Available from: https://cefrio.qc.ca/fr/enquetes-et-donnees/netendances201 7-portrait-numerique-foyers-quebecois/. Archived at : http://www. webcitation.org/76HUcPI6k.

19. Xesfingi S, Vozikis A. eHealth literacy: in the quest of the contributing factors. Interact J Med Res. 2016;5(2):e16.

20. Québec Gd. Plan d'action interministériel 2017-2020 : politique gouvernementale de prévention en santé : un projet d'envergure pour améliorer la santé et la qualité de vie de la population 2018. Available from: http://publications.msss.gouv.qc.ca/msss/fichiers/2017/17-297-02W.pdf. Archived at : http://www.webcitation.org/76HXZ8Duq.

21. Waisel DB. Vulnerable populations in healthcare. Curr Opin Anaesthesiol. 2013;26(2):186-92.

22. Nagler RH, Ramanadhan S, Minsky S, Viswanath K. Recruitment and retention for community-based eHealth interventions with populations of low socioeconomic position: strategies and challenges. J Commun. 2013;63(1):201-20.

23. Ejiogu N, Norbeck JH, Mason MA, Cromwell BC, Zonderman AB, Evans MK Recruitment and retention strategies for minority or poor clinical research participants: lessons from the healthy aging in neighborhoods of diversity across the life span study. Gerontologist. 2011;51(Suppl 1):S33-45.

24. Ellard-Gray A, Jeffrey NK, Choubak M, Crann SE. Finding the Hidden Participant. Int J Qual Methods.2015;14(5):1-10.

25. Eakin EG, Bull SS, Riley K, Reeves MM, Gutierrez S, McLaughlin P. Recruitment and retention of Latinos in a primary care-based physical activity and diet trial: the resources for health study. Health Educ Res. 2007; 22(3):361-71.

26. Cappella JN. Integrating Message Effects and Behavior Change Theories: Organizing Comments and Unanswered Questions. J Commun. 2006; 56(suppl_1):S265-S79.

27. Heerwegh D, Loosveldt G. Explaining the intention to participate in a web survey: a test of the theory of planned behaviour. Int I Soc Res Methodol. 2009;12(3):181-95.

28. Bosnjak M, Tuten TL, Wittmann WW. Unit (non) response in web-based access panel surveys: an extended planned-behavior approach. Psychol Mark. 2005;22(6):489-505. 
29. Aizen I. The theory of planned behavior. Organ Behav Hum Decis Process. 1991;50(2):179-211.

30. McEachan RRC, Conner M, Taylor NJ, Lawton RJ. Prospective prediction of health-related behaviours with the theory of planned behaviour: a metaanalysis. Health Psychol Rev. 2011;5(2):97-144.

31. McDermott MS, Oliver M, Simnadis T, Beck EJ, Coltman T, Iverson D, et al. The theory of planned behaviour and dietary patterns: a systematic review and meta-analysis. Prev Med. 2015;81:150-6.

32. Cote M, Lapointe A, Laramee C, Lemieux S, Desroches S, Belanger-Gravel A, et al. Beliefs related to participation in a large web-based prospective survey on diet and health among individuals with a low socioeconomic status: qualitative study. JMIR Form Res. 2019;3(4):e13854.

33. Rongen A, Robroek SJW, van Wouter G, Lindeboom D, Altink B, Burdorf A. Barriers and facilitators for participation in health promotion programs among employees: a six-month follow-up study. BMC Public Health. 2014; 14:573.

34. Rongen A, Robroek SJW, Burdorf A. The importance of internal health beliefs for employees' participation in health promotion programs. YPMED Preventive Medicine. 2014;67:330-4

35. Rashidian A, Miles J, Russell D, Russell I. Sample size for regression analyses of theory of planned behaviour studies: case of prescribing in general practice. Br J Health Psychol. 2006;11(Pt 4):581-93.

36. Fishbein M, Yzer MC. Using theory to design effective health behavior interventions. Communication Theory. 2003;13(2):164-83.

37. Bissonnette-Maheux V, Provencher V, Lapointe A, Dugrenier M, Dumas AA, Pluye $P$, et al. Exploring women's beliefs and perceptions about healthy eating blogs: a qualitative study. J Med Internet Res. 2015;17(4):e87.

38. Farmer DF, Jackson SA, Camacho F, Hall MA. Attitudes of African American and low socioeconomic status white women toward medical research. J Health Care Poor Underserved. 2007:18(1):85-99.

39. Fishbein M, Ajzen I. Predicting and changing behavior: The reasoned action approach. New York: Psychology Press; 2010. xix, 518-xix, p.

40. Forrest $L$, Mitchell G, Thrupp L, Petelin L, Richardson K, Mascarenhas $L$, et al. Consumer attitudes towards the establishment of a national Australian familial cancer research database by the inherited Cancer connect (ICCon) partnership. J Community Genet. 2018;9(1):57-64.

41. Yamamoto M, Fujita M, Mori C, Hata A. Survey of motivation to participate in a birth cohort. J Hum Genet. 2016;61 (9):787-91.

42. Haas K, Costley D, Falkmer M, Richdale A, Sofronoff K, Falkmer T. Factors influencing the research participation of adults with autism Spectrum disorders. J Autism Dev Disord. 2016;46(5):1793-805.

43. Michie S, Richardson M, Johnston M, Abraham C, Francis J, Hardeman W, et al. The behavior change technique taxonomy (v1) of 93 hierarchically clustered techniques: building an international consensus for the reporting of behavior change interventions. Ann Behav Med. 2013;46(1):81-95

44. Barber J, Kusunoki Y, Gatny H, Schulz P. Participation in an Intensive Longitudinal Study with Weekly Web Surveys Over 2.5 Years. J Med Internet Res. 2016;18(6):e105.

45. Evans MK, Lepkowski JM, Powe NR, LaVeist T, Kuczmarski MF, Zonderman AB. Healthy aging in neighborhoods of diversity across the life span (HANDLS): overcoming barriers to implementing a longitudinal, epidemiologic, urban study of health, race, and socioeconomic status. Ethn Dis. 2010;20(3):267-75.

46. van Gelder MM, Bretveld RW, Roeleveld N. Web-based questionnaires: the future in epidemiology? Am J Epidemiol. 2010;172(11):1292-8.

47. Teague S, Youssef GJ, Macdonald JA, Sciberras E, Shatte A, Fuller-Tyszkiewicz $\mathrm{M}$, et al. Retention strategies in longitudinal cohort studies: a systematic review and meta-analysis. BMC Med Res Methodol. 2018;18(1):151.

48. Edwards PJ, Roberts I, Clarke MJ, Diguiseppi C, Wentz R, Kwan I, et al. Methods to increase response to postal and electronic questionnaires. Cochrane Database Syst Rev. 2009;3:MR000008.

49. Nicholson LM, Schwirian PM, Groner JA. Recruitment and retention strategies in clinical studies with low-income and minority populations: Progress from 2004-2014. Contemp Clin Trials. 2015;45(Pt A):34-40.

50. Hernando C, Sabido M, Casabona J. Facilitators and barriers of participation in a longitudinal research on migrant families in Badalona (Spain): a qualitative approach. Health Soc Care Community. 2018;26(1):e64-74.

51. Fomby P, Sastry N, McGonagle KA. Effectiveness of a time-limited incentive on participation by hard-to-reach respondents in a panel study. Field methods. 2017:29(3):238-51.
52. Yu S, Alper HE, Nguyen AM, Brackbill RM, Turner L, Walker DJ, et al. The effectiveness of a monetary incentive offer on survey response rates and response completeness in a longitudinal study. BMC Med Res Methodol. 2017;17(1):77.

53. Edwards P, Roberts I, Sandercock P, Frost C. Follow-up by mail in clinical trials: does questionnaire length matter? Control Clin Trials. 2004;25(1):3152.

54. Sahlqvist S, Song Y, Bull F, Adams E, Preston J, Ogilvie D. Effect of questionnaire length, personalisation and reminder type on response rate to a complex postal survey: randomised controlled trial. BMC Med Res Methodol. 2011;11(1):62.

55. Fan W, Yan Z. Factors affecting response rates of the web survey: a systematic review. Comput Hum Behav. 2010;26(2):132-9.

56. Koitsalu M, Eklund M, Adolfsson J, Gronberg H, Brandberg Y. Effects of prenotification, invitation length, questionnaire length and reminder on participation rate: a quasi-randomised controlled trial. BMC Med Res Methodol. 2018;18(1):3.

57. Davidson KM, Espie CJ, Lammie C. Conducting randomised controlled trials: finding better ways to explain research to people with anti-social personality disorder who have low literacy levels. Crim Behav Ment Health. 2011;21(4):265-78.

58. Gd Q. Portrait statistique des adultes de 18 à 65 ans sans diplôme d'études secondaires au Québec; 2019.

59. Kripalani S, Heerman WJ, Patel NJ, Jackson N, Goggins K, Rothman RL, et al. Association of Health Literacy and Numeracy with interest in research participation. J Gen Intern Med. 2019;34(4):544-51.

\section{Publisher's Note}

Springer Nature remains neutral with regard to jurisdictional claims in published maps and institutional affiliations.

Ready to submit your research? Choose BMC and benefit from:

- fast, convenient online submission

- thorough peer review by experienced researchers in your field

- rapid publication on acceptance

- support for research data, including large and complex data types

- gold Open Access which fosters wider collaboration and increased citations

- maximum visibility for your research: over $100 \mathrm{M}$ website views per year

At BMC, research is always in progress.

Learn more biomedcentral.com/submissions 